\title{
Jasminum fuchsiifolium (Oleaceae): An addition to the Flora of India
}

\author{
Santanu Dey' ${ }^{1}$ Durgesh Verma ${ }^{2}$, Moaakum $^{3}$, Chaturvedi,S.K. ${ }^{1}$, Jamir, N.S. ${ }^{1}$ and \\ Temjennokha, B. Longchar ${ }^{1}$ \\ 'Department of Botany, Nagaland University, Lumami - 798 627, Nagaland, India \\ 2Botanical Survey of India, Northern Regional Centre, Dehradun - 248 195, Uttarakhand, India \\ ${ }^{3}$ Kohima Science College (Autonomous), Jotsoma, Kohima - 797 002, India \\ *E-mail: moaakumjamir@gmail.com
}

\begin{abstract}
Jasminum fuchsiifolium Gagnep. is reported here as a new addition to the Flora of India. A detailed description and photographic illustration are provided to facilitate easy and correct identification.
\end{abstract}

Keywords: India, Jasminum fuchsiifolium, Nagaland, new record, Oleaceae

\section{Introduction}

The genus Jasminum L., comprises of c. 200 species, is distributed in tropical and subtropical regions of Africa, Australia, Europe and South East Asia (Mabberley, 2008). In India, the genus is represented by 48 species, 3 subspecies and 4 varieties, of which 17 taxa are endemic (Green, 2003; Sabeena et al., 2007), mainly reported from Eastern and Western Himalayas, Deccan Peninsula, Andaman and Nicobar Islands (Srivastava, 2002).

During a floristic exploration in Tuensang district of Nagaland, India, an interesting species of Jasminum was collected by one of the authors (SD). A perusal of relevant literature (Gagnepain, 1933; Chang et al., 1996) and consulting authentic herbarium specimens, the specimens were identified as Jasminum fuchsiifolium Gagnep., a species so far not reported from India. This was further compared and confirmed with the photograph of type specimen deposited at National Museum of Natural History, Paris (P) [available at https://science.mnhn.fr/institution/mnhn/search]. Hereunder, follows a detailed description, ecology and distribution accompanied with photographic illustrations.

Jasminum fuchsiifolium Gagnep., Bull. Soc. Bot. France 80:74.1933; Changetal.inZ.Wu\&P.H. Raven (Eds.), Fl. China 15: 312. 1996.

Figs. 1, 2

Scandent shrubs, up to $2 \mathrm{~m}$ long. Branchlets 4-angled, hollow, glabrous. Leaves opposite, simple, ovate to ovate-lanceolate or narrowly elliptic, $4.0-9.5 \times 1.2-3.5 \mathrm{~cm}$, apex acute or acuminate, base rounded, truncate or cuneate, margin entire or slightly wavy, membranous, adaxial surface dark green, abaxial pale green; primary veins 5-9 on both sides of midrib, arcuate, domatia present in the axils; petioles $0.4-1.0$ $\mathrm{cm}$ long, narrowly winged, glabrous. Flowers scentless, $1.8-2.3 \mathrm{~cm}$ long, in 3-6-flowered lax racemose cymes, or in 3-flowered umbellate cymes. Bracts linear, 3-5 mm long. Pedicels 1.0$2.4 \mathrm{~cm}$ long, thickened at distal end, green. Calyx campanulate, 5-lobed, glabrous, green; tube 2.5$3.0 \mathrm{~mm}$ long; lobes subulate-deltate, 3-4 mm long. Corolla white, salverform; tube 1.0-1.2 cm long, glabrous; lobes 5-8, oblong to lanceolate, $7-9 \mathrm{~mm}$ long, glabrous. Stamens 2, included in corolla tube; anthers 2.5-3.0 mm long, dorsifixed; filaments c. 1 $\mathrm{mm}$ long, glabrous. Ovary barrel-shaped, c. $1 \mathrm{~mm}$, glabrous; style 1.0-1.3 cm long, glabrous; stigma $c$. $3 \mathrm{~mm}$ long, bifid, glabrous. Fruits not seen.

Flowering: July - September.

Specimens examined: INDIA, Nagaland, Tuensang district, Helipong forest area, $26^{\circ} 12^{\prime} 8.88^{\prime \prime} \mathrm{N}$, 94 44'40.47" E, 2123 m, 21.09.2016, S. Dey 254 (BSD!).CHINA, Guizhou, near Jaô-kia-tchay, 02.07.1917, J. Esquirol 6124 (P Image!); KouyTcheou province, $1300 \mathrm{~m}, 22.08 .1917$, J. Esquirol 6202 (P Image!).

Distribution: Northeast India (Nagaland) and China (W. Guangxi, Guizhou, Yunnan). 


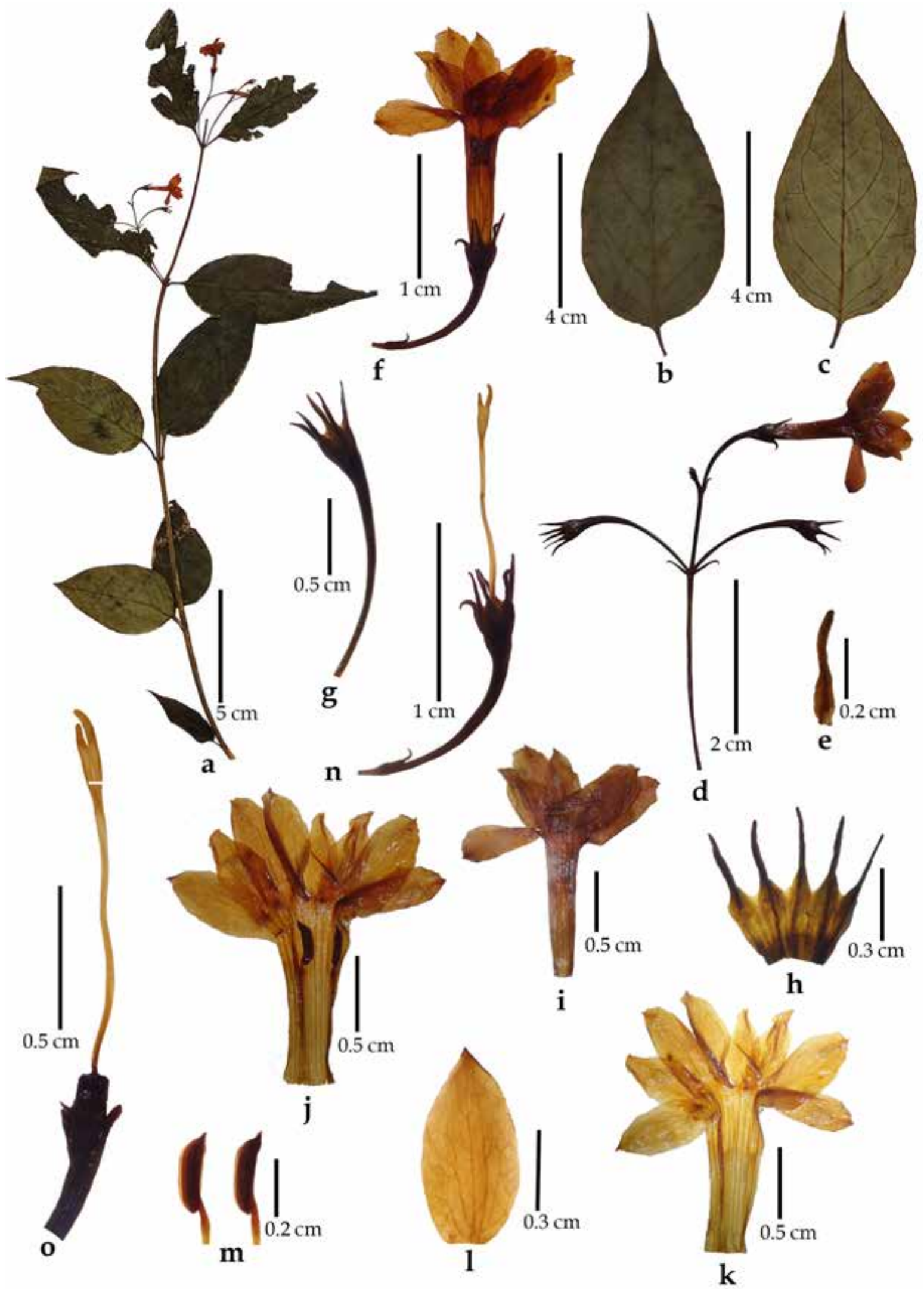

Fig. 1. Jasminum fuchsiifolium Gagnep.: a. Flowering twig; b. Leaf (adaxial view); c. Leaf (abaxial view); d. Inflorescence; e. Bract; f. Flower; g. Calyx with pedicel; $\boldsymbol{h}$. Calyx split-open; $\mathbf{i}$. Corolla; $\mathbf{j}$. Corolla tube split-open to show attachment of stamens; k. Corolla split-open; I. Corolla lobe; $\mathbf{m}$. Stamens; $\mathbf{n}$. Gynoecium with pedicel, calyx and bract; $\mathbf{0}$. Ovary, style and stigma with a portion of pedicel [Photographic illustration by D. Verma based on S.Dey 254]. 


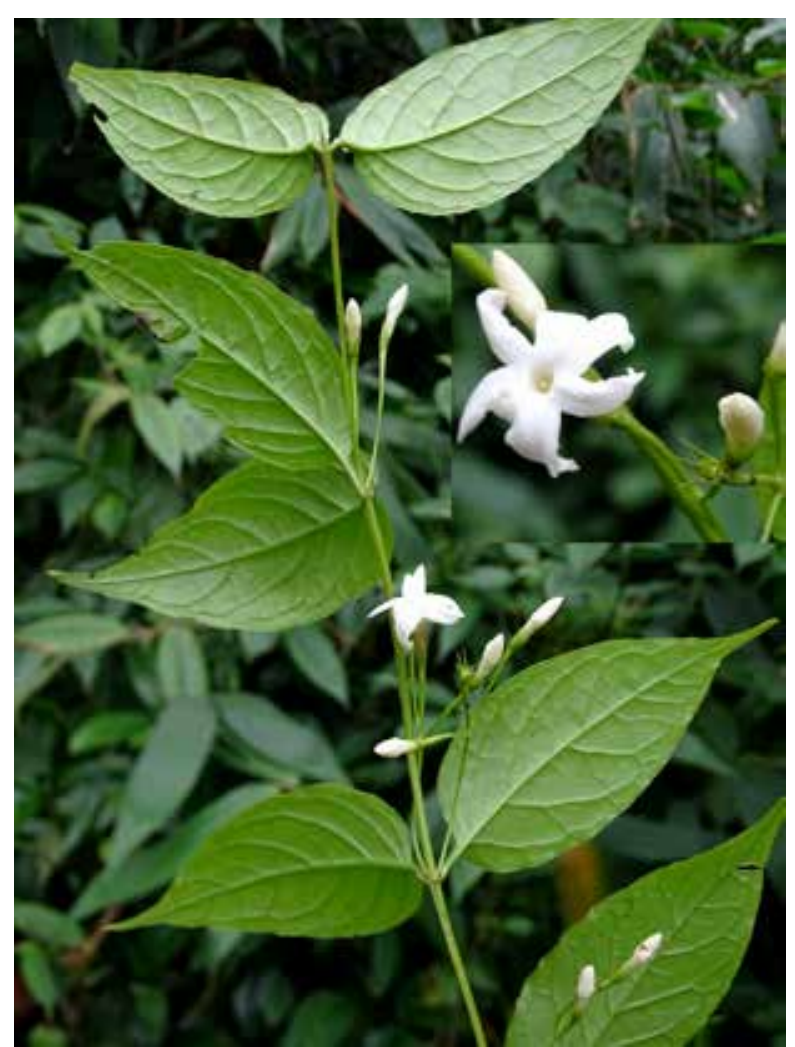

Fig. 2. A flowering twig and flowers enlarged in inset [Photographs by S. Dey].

Habitat and ecology: Found growing at moist shady places near road side areas along hilly slopes in sub-tropical semi evergreen forests amongst Dichroa febrifuga, Laportea terminalis, Strobilanthes sp. and Thelypteris sp.

Notes: The species was first described by Gagnepain (1933) based on the collections made by J. Esquirol in 1917 from Guizhou, China. Only few specimens of these collections are deposited at Paris (P). The present collections form a new report of this species from Nagaland (NE India), and it represents an extension of its distribution in South Asia. Extensive field surveys are required to ascertain its distribution and conservation status.

\section{Acknowledgements}

The authors are grateful to Dr. R.K. Choudhary, Biodiversity \& Palaeobiology Group, Agharkar Research Institute, Pune, India and Dr. Bui Hong Quang, Department of Botany, Institute of Ecology and Biological Resources, Vietnam Academy of Science and Technology, Hanoi, Vietnam for helping in the identity of plant. DV is thankful to Dr. P. Singh, Director, Botanical Survey of India (BSI), Kolkata, and to the Head of Office, BSI, Northern Regional Centre, Dehradun for facilities and encouragement.

\section{Literature Cited}

Chang, M.C., Qui, L.Q., Wei, Z. \& P.S. Green 1996. Jasminum. In: Wu, Z. \& P.H. Raven (Eds.). Flora of China Vol. 15. Science Press, Beijing, Missouri Botanical Garden Press, St. Louis, U.S.A. pp. 307-319.

Gagnepain, F. 1933. Oléacées nouvellesd' Indochine. Bull. Soc. Bot. France. 80(1): 73-78.

Green, P.S. 2003. Synopsis of the Oleaceae from the Indian Sub-Continent. Kew Bull. 58(2): 257-295.

Mabberley, D.J. 2008. Mabberley's Plant-Book: A portable dictionary of plants, their classification and uses. Cambridge University Press, England. p. 1019.

Sabeena, A., Mestry, A., Mulani, R.M., Kumar, E.S.S. \& N.T. Sibin 2007. A new species of Jasminum L. (Oleaceae) from Kerala, India. Indian J. Forest. 30(1): 123-125.

Srivastava, S.K. 2002. Threatened taxa of Jasminum L. in India. Phytotaxonomy 2: 94-99.

Received: 28.06.2017

Revised and Accepted: 14.06.2018 